\title{
Zmiany elektrokardiograficzne u pacjenta z zatrzymaniem krążenia w przebiegu niewyrównanej cukrzycy i niewydolności nerek
}

\author{
Electrocardiographic changes in a patient with cardiac arrest \\ in the course of uncontrolled diabetes and renal insufficiency
}

\author{
Igor Chęciński ${ }^{1}$, Grzegorz Gogolewski ${ }^{2}$, Przemysław Skoczyński ${ }^{2}$, Dorota Zyśko ${ }^{1}$ \\ ${ }^{1}$ Zakład Ratownictwa Medycznego Uniwersytetu Medycznego im. Piastów Śląskich we Wrocławiu \\ ${ }^{2}$ Katedra i Klinika Medycyny Ratunkowej Uniwersytetu Medycznego im. Piastów Śląskich we Wrocławiu
}

\section{Streszczenie}

Leczenie pacjenta z zatrzymaniem krążenia w przebiegu rytmów niedefibrylacyjnych wymaga poszukiwania potencjalnie odwracalnych przyczyn. Nieoznaczalne stężenie glukozy w badaniu glukometrem nasuwa podejrzenie kwasicy cukrzycowej, odwodnienia i hiperkaliemii jako przyczyn zatrzymania krążenia. W przypadku dostępnego zapisu elektrokardiograficznego (EKG), wykonanego bezpośrednio przed zatrzymaniem krążenia lub po skutecznej resuscytacji, należy poszukiwać cech EKG sugerujących hiperkaliemię. W pracy przedstawiono przypadek chorego z dwoma incydentami zatrzymania krążenia w przebiegu kwasicy cukrzycowej i hiperkaliemii oraz omówiono zapis EKG u tego pacjenta.

Słowa kluczowe: nagłe zatrzymanie krążenia, kwasica cukrzycowa, elektrokardiogram, hiperkaliemia

Folia Cardiologica 2017; 12, 6: 611-614

\section{Wstęp}

Wystąpienie zatrzymania krążenia w mechanizmie rytmów niedefibrylacyjnych jest wskazaniem do poszukiwania potencjalnie odwracalnych przyczyn, do których należą zaburzenia metaboliczne, w tym elektrolitowe. Hiperkaliemia może prowadzić do powstania różnych obrazów elektrokardiograficznych (EKG): spiczastych załamków T, poszerzenia zespołu QRS, wydłużenia odstępu PR, zaniku załamków P przy utrzymaniu się czynności rozrusznika w węźle zatokowo-przedsionkowym, bardzo szerokich zespołów QRS, które zlewają się z załamkami T, tworząc obraz sinusoidy, wolnego rytmu komorowego, asystolii czy migotania komór [1-3]. Według niektórych autorów załamki P mogą być niewidoczne w czasie rytmu zatokowego przewodzonego do komór, ponieważ komórki mięśnia przedsionków są bardziej wrażliwe na podwyższone stężenie potasu niż komórki mięśnia komór i rytm ten jest bardzo specyficzny dla hiperkaliemii [1].

W niniejszej pracy przedstawiono zapisy EKG pacjenta z ciężkimi zaburzeniami metabolicznymi w przebiegu źle kontrolowanej cukrzycy.

\section{Opis przypadku}

Mężczyzna 68-letni z wieloletnią cukrzycą leczoną insuliną, który nie kontrolował ostatnio glikemii, zgłosił nasilone osłabienie i wymioty, co było powodem wezwania zespołu ratownictwa medycznego (ZRM). Stężenie glukozy było nieoznaczalne glukometrem. Po wykonaniu EKG przez ZRM (ryc. 1) u pacjenta wystąpiło nagłe zatrzymanie krążenia w mechanizmie asystolii. Pacjenta skutecznie zresuscytowano.

Adres do korespondencji: dr n. med. Dorota Zyśko, Zakład Ratownictwa Medycznego, Wydział Nauk o Zdrowiu, Uniwersytet Medyczny im. Piastów Śląskich we Wrocławiu, ul. Bartla 5, 51-618 Wrocław, faks 7173312 09, e-mail: dzysko@wp.pl 


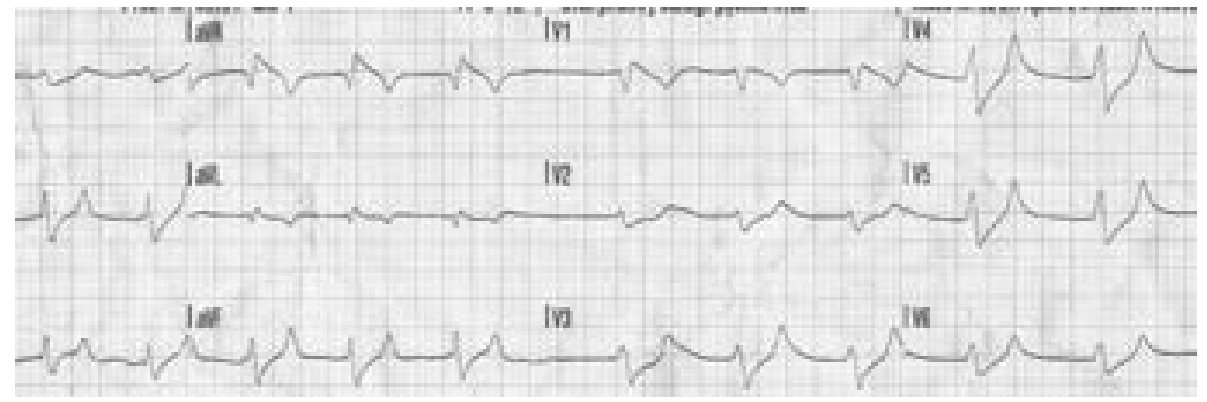

Rycina 1. Zapis elektrokardiograficzny przed wystąpieniem zatrzymania krążenia w mechanizmie asystolii - rytm z szerokimi zespołami QRS, częstość komór średnio 75/min, QRS 220 ms, morfologia przypominająca blok prawej odnogi pęczka Hisa, QT 440 ms

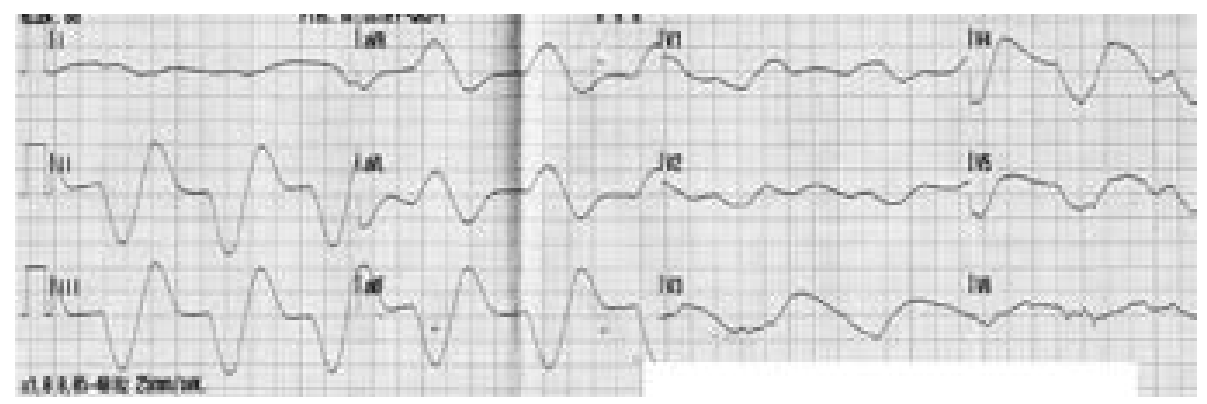

Rycina 2. Zapis elektrokardiograficzny po resuscytacji - rytm komorowy 75/min, QRS 320 ms, QT 680 ms, dodatnie załamki R w odprowadzeniu aVR wskazujące na komorowe pochodzenie arytmii serca

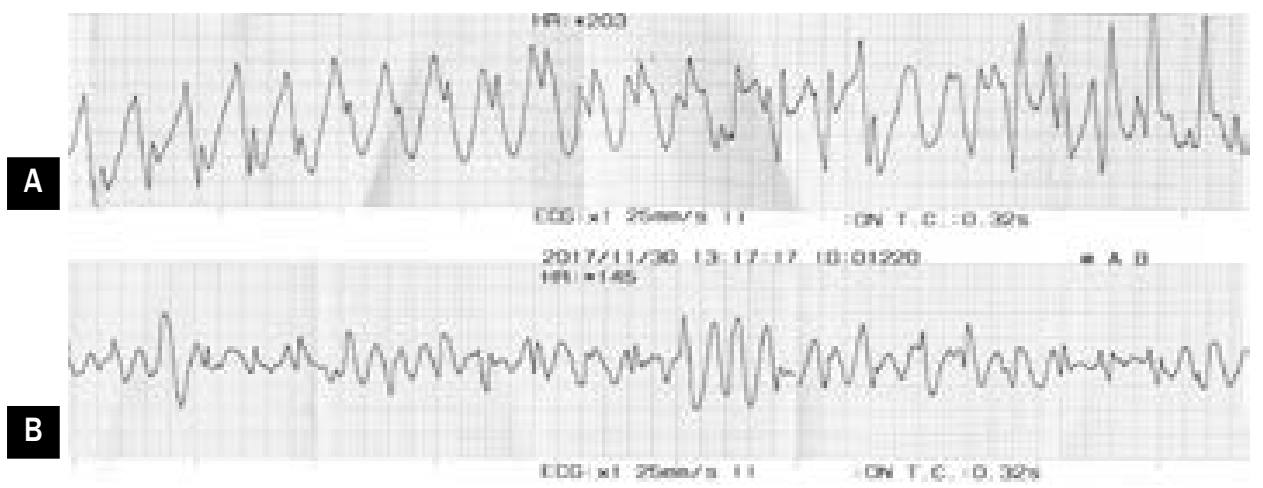

Rycina 3A, B. Zapis elektrokardiograficzny wykonany po przewiezieniu na szpitalny oddział ratunkowy: A. Polimorficzny częstoskurcz komorowy 200/min; B. Migotanie komór

Zapis EKG po resuscytacji przedstawiono na rycinie 2. Po zatrzymaniu krążenia nieprzytomny, wentylowany mechanicznie 100-procentowym tlenem pacjent został przewieziony na szpitalny oddział ratunkowy (SOR), gdzie bezpośrednio po przyjęciu wystąpiło zatrzymanie krążenia w mechanizmie migotania komór, poprzedzonego częstoskurczem komorowym (ryc. 3A, B), które przerwano defibrylacją $200 \mathrm{~J}$. Po defibrylacji obserwowano rytm z wąskimi zespołami QRS 90/min, a następnie rytm zatokowy (ryc. 4). Przy przyjęciu na SOR w badaniu parametrów krytycznych z użyciem analizatora firmy Radiometer stwierdzono kwasicę metaboliczną z hipokapnią, hiperoksję, duży niedobór wodorowęglanów, stężenie potasu 9,1 mmol/l, stężenie mleczanów $10 \mathrm{mmol} / \mathrm{l}$, stężenie kreatyniny $3,3 \mathrm{mg} / \mathrm{dl}$, stężenie sodu $122 \mathrm{mEq} / \mathrm{I}$ z nieoznaczalnym stężeniem glukozy. Stężenie glukozy oznaczone później w laboratorium szpitalnym wynosiło $1700 \mathrm{mg} / \mathrm{dl}$.

Pacjentowi podano wlew soli fizjologicznej, insuliny, wodorowęglanu sodu, chlorku wapnia oraz sulfonian polistyrenu przez sondę żołądkową. Uzyskano częściową normalizację parametrów biochemicznych. Chory pozostawał nieprzytomny; ze względu na hipotonię wymagał wlewu amin katecholowych. Zdecydowano o przekazaniu go na oddział intensywnej terapii, gdzie mimo intensywnego 


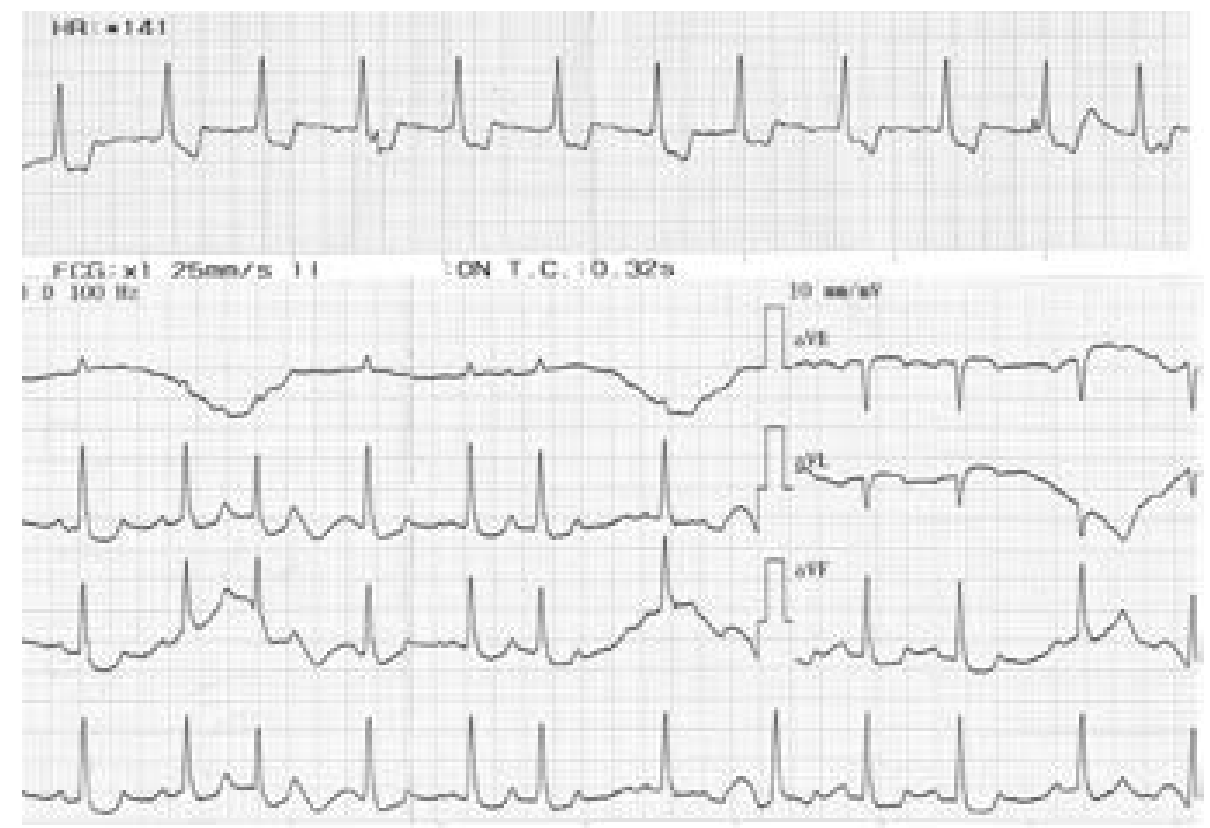

Rycina 4. Zapis elektrokardiograficzny po defibrylacji - rytm węzłowy z wąskimi zespołami QRS po defibrylacji, a następnie rytm zatokowy 93/min., pojedyncze dodatkowe pobudzenia przedsionkowe

leczenia nie odzyskał świadomości i po przeprowadzeniu wymaganych ustawowo badań rozpoznano śmierć mózgu.

\section{Dyskusja}

Hiperkaliemia jest jedną z potencjalnie odwracalnych przyczyn zatrzymania krążenia, choć nie zawsze jest łatwa do rozpoznania. Czynniki sprzyjające wystąpieniu hiperkaliemii to cukrzyca, niewydolność nerek oraz stosowanie niektórych leków.

Obraz EKG może nasuwać podejrzenia hiperkaliemii, co zwłaszcza w warunkach braku możliwości oznaczenia stężenia potasu może mieć duże znaczenie diagnostyczne. W prezentowanym przypadku na hiperkaliemię wskazywały rytm z szerokimi zespołami QRS z częstością komór 75/min i brak załamków P (ryc. 1). Zapis taki opisywano jako rytm zatokowo-komorowy. Wysokie stężenie potasu hamuje aktywność ośrodków ektopowych i zwalnia przewodnictwo. Bardziej prawdopodobne są czynny rytm węzłowy oraz zwolnienie depolaryzacji mięśnia sercowego, a szczególnie prawej komory, na co wskazuje obraz EKG zespołów QRS z szerokim załamkiem $S$ w odprowadzeniach lewokomorowych na rycinie 1 . Nie można też wykluczyć, że hiperkaliemia i współistniejąca kwasica w pewnym momencie prowadzą do wolnego rytmu komorowego w następstwie fali nawrotnej z dużą zmiennością morfologii i szerokości zespołów QRS z ich tendencją do poszerzania się, co obserwowano w zapisie po zatrzymaniu krążenia w warunkach przedszpitalnych (ryc. 2). Poprawa profilu biochemicznego paradoksalnie może prowadzić do przyspieszenia rytmu komór oraz wystąpienia częstoskurczu komorowego o zmiennej morfologii zespołów QRS, a następnie migotania komór. U opisywanego pacjenta po defibrylacji stwierdzono rytm z wąskimi zespołami QRS; na pierwszym pasku zapisu z monitora nie stwierdzono załamków $P$, które były widoczne w wykonanym później badaniu EKG (ryc. 4) w czasie częściowej normalizacji zaburzeń biochemicznych. Prezentowane zapisy należy oceniać w kontekście wywiadu chorobowego pacjenta oraz podejrzenia bardzo wysokiego stężenia glukozy, którego nie można było ocenić za pomocą testów paskowych. Kwasica cukrzycowa jest jedną z okoliczności typowych dla wystąpienia hiperkaliemii. W zapisach rytmu serca z monitora defibrylatora na SOR stwierdzano częstoskurcz komorowy, a następnie migotanie komór, które jedynie chwilowo przypominało sinusoidę. Rozpoznania hiperkaliemii dokonano na podstawie badania parametrów krytycznych po przyjęciu na SOR. Mimo intensywnego leczenia i poprawy parametrów biochemicznych stan pacjenta nie poprawił się; chory nadal był nieprzytomny, miał zaburzenia hemodynamiczne wymagające wlewu amin katecholowych. Ciężka kwasica metaboliczna i zatrzymanie krążenia spowodowały nieodwracalne uszkodzenie narządów, w tym mózgu, co ostatecznie doprowadziło do śmierci mózgu. Ciężka hiperkaliemia jest czynnikiem złego rokowania u pacjentów z niewydolnością nerek, cukrzycą czy niewydolnością serca $[4,5]$. 


\section{Wnioski}

Zapis EKG u pacjenta po zatrzymaniu krążenia może zawierać ważne dane uzupełniające do wywiadu chorobowego. Podejrzenie hiperkaliemii wymaga natychmiastowego wdro- żenia odpowiedniej terapii. Zwłoka w podjęciu stosownych działań może negatywnie wpływać na rokowanie chorego.

\section{Konflikt interesów}

Autorzy nie zgłaszają konfliktu interesów.

\section{Abstract}

Treatment of a patient with cardiac arrest in non-shockable rhythms requires searching for potentially reversible causes. An unmeasurable blood glucose concentration in the glucometer test raises suspicion of diabetic acidosis, dehydration and hyperkalemia as a cause of cardiac arrest. In the case of available electrocardiography (ECG) performed immediately before cardiac arrest or after effective resuscitation, electrocardiographic features suggestive of hyperkalemia should be sought. The paper presents a case of the patient with 2 incidents of cardiac arrest in the course of diabetic acidosis and hyperkalemia. The electrocardiographic records of this patient are discussed.

Key words: cardiac arrest, diabetic acidosis, electrocardiogram, hyperkalemia

Folia Cardiologica 2017; 12, 6: 611-614

\section{Piśmiennictwo}

1. Ross AM, Proper MC, Aronson AL. Sinoventricular conduction in atrial standstill. J Electrocardiol. 1976; 9(2): 161-164, doi: 10.1016/s0022 -0736(76)80070-2, indexed in Pubmed: 1262775.

2. Durfey N, Lehnhof B, Bergeson A, et al. Severe hyperkalemia: can the electrocardiogram risk stratify for short-term adverse events? West J Emerg Med. 2017; 18(5): 963-971, doi: 10.5811/westjem. 2017.6.33033, indexed in Pubmed: 28874951.

3. Parham WA, Mehdirad AA, Biermann KM, et al. Hyperkalemia revisited. Tex Heart Inst J. 2006; 33(1): 40-47, indexed in Pubmed: 16572868.
4. Thomsen RW, Nicolaisen SK, Hasvold P, et al. Elevated potassium levels in patients with chronic kidney disease: occurrence, risk factors and clinical outcomes-a Danish population-based cohort study. Nephrol Dial Transplant. 2017 [Epub ahead of print], doi: 10.1093/ndt/ /gfx312, indexed in Pubmed: 29177463.

5. Huang CW, Lee MJ, Lee PT, et al. Low potassium dialysate as a protective factor of sudden cardiac death in hemodialysis patients with hyperkalemia. PLoS One. 2015; 10(10): e0139886, doi: 10.1371/ /journal.pone.0139886, indexed in Pubmed: 26440515. 


\section{Komentarz}

\section{Czy w ogóle mieliśmy szansę?}

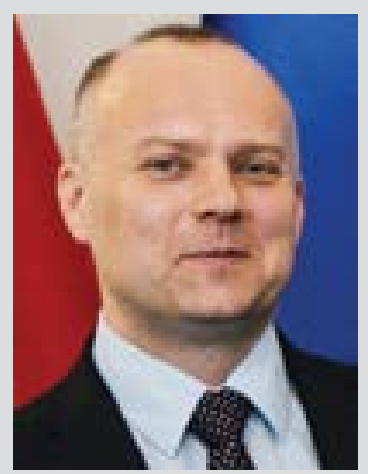

\section{prof. dr hab. n. med. Jacek Gajek}

Zakład Pielęgniarstwa Internistycznego

Uniwersytetu Medycznego im. Piastów Śląskich we Wrocławiu

Nasilona hiperkaliemia jest stanem bezpośrednio zagrażającym życiu, o czym przekonuje nas, po raz kolejny, przedstawiony przypadek chorego z kwasicą metaboliczną, niewyrównaną cukrzycą i niewydolnością nerek [1]. Autorzy za punkt wyjścia opisu przypadku przyjęli zmiany elektrokardiograficzne (EKG) u chorego, przyjmę je zatem i ja, skoncentruję się jednak na możliwości uratowania pacjenta w opisanym stanie.

Zapis EKG przedstawiony na rycinie 1 artykułu jest typowy dla hiperkaliemii przekraczajacej wartość 7,0-8,0 mEq/l. Dość szeroki zakres wartości stężenia potasu nie jest, niestety, dostatecznie precyzyjny, jednak nie o wartości tu chodzi, a o nasilone cechy toksyczności potasu - brak załamków P oraz zaburzenia depolaryzacji i repolaryzacji komór. Opisywany chory jest w tym czasie jeszcze przytomny, co jest dość niezwykłe, zważywszy na opisane następnie zaburzenia metaboliczne, jednak fakt ten z pewnością ułatwiał diagnostykę różnicową i umożliwiał szybkie działanie. Zebrany wywiad chorobowy wraz z zapisem EKG jednoznacznie wskazywały na możliwość hiperkaliemii, którą należało leczyć niezwłocznie, wszelkimi dostępnymi środkami. Ponadto obraz sugerował również kwasicę metaboliczną, która przyczyniała się do wzrostu stężenia potasu w surowicy krwi i także wymagała leczenia. Brak możliwości oznaczenia stężenia glukozy glukometrem wskazuje na jej bardzo wysokie stężenia, zwykle przekraczające wartości $700-800 \mathrm{mg} / \mathrm{dl}$ i dla ratowników medycznych nie powinien być czynnikiem deprymującym. W zespole ratownictwa medycznego do dyspozycji są następujące leki: 0,9-proc. roztwór chlorku sodu, roztwór 8,4-proc. wodorowęglanu sodu, furosemid oraz salbutamol [2]. Wydaje się, że w opisanym przypadku należałoby wszystkie te leki podać dożylnie jednocześnie, w „ciemno”, gdyż ich niezastosowanie skutkowało pogorszeniem stanu chorego i asystolią odpowiedzialną za pierwsze zatrzymanie krążenia. Należy również dodać, że podanie wymienionych wyżej substancji u chorego bez wymienionych zaburzeń nie miałoby w zasadzie negatywnego wpływu na jego stan zdrowia. Wśród wymienionych leków nie ma najważniejszego, z punktu widzenia ochrony mięśnia sercowego, a nie wpływającego na stężenie potasu - roztworu chlorku wapnia. Jego dożylne zastosowanie u chorego z hiperkaliemią skutkuje względnie szybką normalizacją zapisu EKG, oddalającą możliwość asystolii, jak również migotania komór. Odrębnym zagadnieniem było, czy gwałtownie pogarszający się stan chorego pozwalał na takie działania.

Typowa resuscytacja w asystolii obejmuje podanie dożylnie adrenaliny. Lek beta-mimetyczny podano, lecz obraz EKG wyraźnie się pogorszył. Na rycinie $2 \mathrm{w}$ artykule widzimy rytm komorowy z bardzo szerokimi zespołami QRS, sięgającymi prawie $400 \mathrm{~ms}$. Taki obraz sugeruje stężenia potasu przekraczające $8 \mathrm{mEq} / \mathrm{L} \mathrm{i} \mathrm{jest} \mathrm{dowodem} \mathrm{na} \mathrm{pogarszającą} \mathrm{się}$ w przebiegu zatrzymania krążenia kwasicę metaboliczną. Doprowadza ona do przesunięcia jonów potasu do przestrzeni pozakomórkowej. Zapis EKG ponownie jest typowy i wskazuje na pilną konieczność zastosowania wszystkich wspomnianych uprzednio leków, na które teraz jest już czas - chory jest transportowany przez kilkanaście do kilkudziesięciu minut na szpitalny oddział ratunkowy (SOR).

Po przyjęciu na SOR pacjent ponownie nie daje szans przyczynowym działaniom ratującym życie - bezpośrednio po przyjęciu następuje nagłe zatrzymanie krążenia w mechanizmie migotania komór. Resuscytacja ponownie jest skuteczna. Wykonane następnie czynności i podane leki skutkują powrotem rytmu zatokowego z obrazem wąskich zespołów QRS, lecz ostatecznie całość postępowania jest nieskuteczna. U chorego dochodzi do nieodwracalnego uszkodzenia mózgu i zgonu. Najbardziej prawdopodobnymi przyczynami tego uszkodzenia, poza oczywistym wpływem dwukrotnego nagłego zatrzymania krążenia, są kwasica metaboliczna, nasilona hiperglikemia i, być może, jej (zbyt szybkie) obniżanie [3]. Badacze zajmujący się leczeniem kwasicy metabolicznej w cukrzycy już bardzo dawno temu wskazywali na możliwość uszkodzenia mózgu w mechanizmie jego obrzęku, który mógł prowadzić do zgonu mimo wczesnej poprawy klinicznej stanu chorego oraz jego parametrów biochemicznych [4, 5]. Wskazywano również na inne czynniki mogące wywoływać obrzęk mózgu, takie jak sama kwasica metaboliczna oraz niedotlenienie, jednak zawsze elementem nadrzędnym była istotne różnica stężeń glukozy w płynie mózgowo-rdzeniowym i krwi, determinująca akumulację wody w tkance mózgowej. W licznych opisach przypadków wskazuje się na możliwość uszkodzenia mózgu w trakcie 
wyrównywania zaburzeń metabolicznych, przy czym uszkodzenie to nie poddawało się na przykład stosowaniu steroidów, prowadząc do zgonu [6].

Próba odpowiedzi na pytanie zadane na wstępie rozważań, o możliwość uratowania przedstawionego chorego, prowadzi do konkluzji, że szanse na utrzymanie pacjenta przy życiu były znikome. Należy jednak podkreślić, że zarówno okoliczności kliniczne, jak i zapisy EKG chorego były typowe dla rozpoznania hiperkaliemii i zastosowanie właściwego postępowania mogłoby odwrócić niekorzystny przebieg zdarzeń, w tym powstrzymać zatrzymania krążenia. Trzeba w tym przypadku wskazać na konieczność stałego doskonalenia umiejętności oraz wzbogacania wiedzy dotyczącej zaburzeń EKG w różnych stanach nagłych, czego dobrym, choć - niestety - smutnym przykładem jest opisany przypadek. Należy ponadto prowadzić stałą akcję edukacyjną osób z chorobami przewlekłymi, których zaostrzenia mogą stanowić nagłe zagrożenie dla ich życia. Ale to już zupełnie inna historia...

\section{Piśmiennictwo}

1. Montoliu J, Revert L. Lethal hyperkalemia associated with severe hyperglycemia in diabetic patients with renal failure. Am J Kidney Dis. 1985; 5(1): 47-48, indexed in Pubmed: 3966469.

2. Rozporządzenie ministra zdrowia z 29 grudnia $2006 \mathrm{r}$. w sprawie szczegółowego zakresu medycznych czynności ratunkowych, które mogą być podejmowane przez ratownika medycznego (Dz.U. z 2007 r. nr 4, poz. 33). Nowelizacja rozporządzenia 20 kwietnia 2016 r. w sprawie medycznych czynności ratunkowych i świadczeń zdrowotnych innych niż medyczne czynności ratunkowe, które mogą być udzielane przez ratownika medycznego.

3. Hayes TM, Woods $\mathrm{CJ}$. Unexpected death during treatment of uncomplicated diabetic ketoacidosis. Br Med J. 1968; 4(5622): 32-33, indexed in Pubmed: 4971101.
4. An JN, Lee JP, Jeon HJ, et al. Severe hyperkalemia requiring hospitalization: predictors of mortality. Crit Care. 2012; 16(6): R225, doi: 10.1186/cc11872, indexed in Pubmed: 23171442.

5. Tay S, Lee IL. Survival after cardiopulmonary arrest with extreme hyperkalaemia and hypothermia in a patient with metformin-associated lactic acidosis. BMJ Case Rep. 2012; 2012, doi: 10.1136/bcr-2012-007804, indexed in Pubmed: 23264158.

6. Makino J, Uchino S, Morimatsu $\mathrm{H}$, et al. A quantitative analysis of the acidosis of cardiac arrest: a prospective observational study. Crit Care. 2005; 9(4): R357-R362, doi: 10.1186/cc3714, indexed in Pubmed: 16137348. 